\title{
Allometric growth in the skull of Tylosaurus proriger (Squamata: Mosasauridae) and its taxonomic implications
}

\author{
Robert F. Stewart ${ }^{1}$ and Jordan C. Mallon ${ }^{2, *}$ \\ ${ }^{1}$ Department of Earth Sciences, Carleton University, Ottawa, Ontario, Canada, K1S 5B6; rfmstewart@gmail.com \\ ${ }^{2}$ Palaeobiology, Canadian Museum of Nature, PO Box 3223, Station D, Ottawa, Ontario, Canada, K1P 6P4; \\ jmallon@nature.ca
}

\begin{abstract}
Ontogeny-the growth and development of an organism-is among the more poorly understood aspects of the life history of mosasaurs, largely owing to a dearth of fossil material from young individuals. We describe the partial and nearly complete skulls of two subadult individuals of the mosasaurid Tylosaurus proriger from the upper Smoky Hills Chalk Member of the Niobrara Formation (upper Santonian) in Kansas. We include the more complete of the two specimens in an allometric analysis to better understand proportional changes in the skull through growth. Although our small sample size produces several instances of 'soft isometry', we recover the length of the edentulous rostrum as significantly negatively allometric, and quadrate height as significantly positively allometric. In light of our findings, we consider the question of whether T. kansasensis represents an immature ontogimorph of T. nepaeolicus, and find substantive evidence to reject this hypothesis.
\end{abstract}

\section{INTRODUCTION}

Mosasauridae is a clade of carnivorous, mostly marine reptiles known from Upper Cretaceous deposits worldwide (Russell, 1967). Aspects of the appearance and life history of its members are well-documented, owing to the excellent fossil record of the family, with some remarkable specimens even retaining traces of soft tissue. These have illuminated issues of mosasaur locomotion (Lindgren et al. 2009), colouration (Lindgren et al. 2010), and physiology (Lindgren et al., 2013).

Despite these advances, the ontogeny of mosasaurs remains poorly understood, owing to a lack of reported growth series. Caldwell (1996, 2007), Pellegrini (2007), and Field et al. (2015) have discussed various aspects of mosasaur ontogeny, but not the suite of gross morphological changes that attends it. This gap in our knowledge is regrettable, as an understanding of ontogeny is key to both developing a robust taxonomy and understanding of a species' ecology (Hone et al., 2016).

Here, we describe a partial and a complete skull attributable to sub-adults of $T$. proriger, a particularly large $(>12 \mathrm{~m}$ long) species known exclusively from the Western Interior

Published July 23, 2018

*corresponding author. $\odot 2018$ by the authors submitted May 24, 2018; revisions received July 7, 2018; accepted July 18, 2018. Handling editor: Robert Holmes. DOI 10.18435/vamp29339
Seaway of North America (Williston 1898; Russell 1967; Everhart 2017). These are among the smallest skulls known for the species, and they help to elucidate the allometric changes undergone by $T$. proriger through life. We conclude by considering how these changes relate to the recent suggestion that T. kansasensis represents a young ontogenetic tage of T. nepaeolicus (Jiménez-Huidobro et al., 2016).

\section{MATERIALS AND METHODS}

The first of the two individuals described here is a nearly complete and mostly articulated panel-mounted skull (CMN 8162), visible in dorsal view. Only the coronoids are missing. The palate and much of the braincase are inaccessible.

The second individual is a partial cranium consisting of a supraoccipital (CMN 51263), right quadrate (CMN 51262), right (CMN 51261) and left prootic (CMN 51260), and fused parietals (CMN 51258). Although each of these elements was given a separate collection number, their similar size, complementarity (the prootics fit to the parietal), year of discovery, state of preservation, and geographic proximity strongly indicate that they pertain to a single individual. These elements are subequal in size to those of CMN 8162 and are preserved in isolation, making them suitable compliments for description. A fifth element, a fused basioccipital-basisphenoid (CMN 51259), is also attributable to the second individual but has been lost. However, Lyons et al. (2000) have figured the specimen and made available a low-resolution (50,000 polygons) $3 \mathrm{D}$ 
model. Black and white photographs of the element are also available at the Canadian Museum of Nature. The basioccipital-basisphenoid is therefore described on the basis of the available photographs and model.

Both of the skulls described here were collected by George F. Sternberg from the Smoky Hills Chalk Member of the Niobrara Formation (upper Santonian) in Logan County, Kansas in 1911, and were purchased by the Canadian Museum of Nature in 1912. The limited locality information available suggests that the specimens are from the upper portion of the member (M. Everhart, pers. com. to JCM, 2016) from which $T$. proriger is exclusively known (Everhart 2001; Carpenter 2008).

Although CMN 8162 was initially referred to the hypodigm of T. proriger by Russell (1967), no reasons were provided. Given that size can vary interspecifically as well as ontogenetically, we were reluctant to assume either the taxonomic or ontogenetic status of the specimen based on size alone. We therefore tested Russell's taxonomic hypothesis by variably including and excluding the specimen from seven allometric regressions of skull measurements for $T$. proriger (described below), using one-way analysis of covariance (ANCOVA) to detect significant differences in adjusted means and slopes. Statistical insignificance was interpreted as support for the hypothesis that CMN 8162 is T. proriger. We examined allometry in the skull of $T$. proriger using the linear morphometric dataset of Everhart (2002), itself modified from Russell (1967). The measurements used in these studies were as follows: length of the skull along the midline (basal skull length, premaxilla to occipital condyle), length of the edentulous premaxillary rostrum, width of the frontal between the orbits, length between the first and sixth maxillary teeth, height of the quadrate, length of the lower jaw, length of the dentary, and length between the first and sixth dentary teeth. Details regarding the landmarks used for these measurements are given in Russell (1967:208). Measurements from eight other T. proriger specimens (CMN 8162, FFHM 1997-10, GSM 1, KUVP 66129, ROM 7906, ROM 59785, TMP 1982.050.0100, YPM VPPU 012000) were added to the dataset, for a total of 14 specimens (Appendix 1). The measurements were log-transformed to linearize relationships among them. Seven of the variables were then plotted against basal skull length (a proxy for body size) and evaluated for allometry using reduced major axis (RMA) regression. We performed all analyses in PAST version 3.12 (Hammer et al., 2001).

\section{Institutional abbreviations: $\mathrm{AMNH}$, American} Museum of Natural History, New York, New York; CMN, Canadian Museum of Nature, Ottawa, Ontario; FFHM, Fick Fossil History Museum, Oakley, Kansas; FHSM, Fort Hays Sternberg Museum, Fort Hays, Kansas; GSM, Georgia Southern Museum, Statesboro, Georgia; HMG,
Hobetsu Museum, Hokkaido, Japan; KUVP, University of Kansas, Museum of Natural History, Lawrence, Kansas; RMM, Red Mountain Museum, Birmingham, Alabama; ROM, Royal Ontario Museum, Toronto, Ontario; TMP, Royal Tyrrell Museum of Palaeontology, Drumheller, Alberta; USNM, United States National Museum, Washington, D. C.; YPM, Yale Peabody Museum, New Haven, Connecticut.

Anatomical abbreviations: a, angular; ala, alar process of basisphenoid; ar, articular; ax, axis; bo, basioccipital; bpt, basipterygoid process; bs, basisphenoid; bt, basal tuber; c3, cervical vertebra 3; ca, anterior semicircular canal; ch, horizontal semicircular canal; cp, posterior semicircular canal; $\mathrm{d}$, dentary; f, frontal; fm, foramen magnum; fo, fenestra ovalis; icb, branch of internal carotid artery; isp, infrastapedial process; $j$, jugal; la, lagena; $\mathrm{m}$, maxilla; mc, medullary cavity; nfo, nutrient foramina; oc, occipital condyle; opc, opisthotic contact; oto ala, otosphenoidal ala; p, parietal; paf, parietal fenestra; pala; parietal ala; pm, premaxilla; pof, postorbitofrontal; prf, prefrontal; pt, pterygoid; q, quadrate; s, splenial; sa, surangular; socr, supraoccipital crest; sp, stapedial pit; sq, squamosal; ssp, suprastapedial process; ta, tympanic ala; u, utricle; V, trigeminal nerve; VII, facial nerve; VIII, acoustic nerve; ?, unknown element.

\section{DESCRIPTION}

The following description is primarily based on CMN 8162 , with supplementary information provided by the second individual (CMN 51258-51263) where noted.

\section{Premaxilla}

The fused premaxillary unit anteriorly tapers to form a blunted and edentulous rostrum (Fig. 1), typical of Tylosaurus (Russell, 1967). The rostrum extends $42 \mathrm{~mm}$ in advance of the first of two premaxillary teeth on either side of the midline. The dorsal surface of the premaxillary body is smooth and arched, and the element is approximately oval in cross-section. There are between four and seven foramina clustered around the anterior tip of the rostrum on either side. These foramina are oval and relatively shallow compared to large Tylosaurus specimens (e.g., HMG-1288 and FFHM 1997-10). Near mid-length, the premaxilla narrows posteriorly, where it forms the dorsal margin of the external naris (internarial bar). The undistorted left external naris is $123 \mathrm{~mm}$ long and $13 \mathrm{~mm}$ wide. The posterior margin of the naris, formed by the junction of the premaxilla, maxilla, and frontal, occurs above the tenth maxillary tooth. The premaxilla interdigitates with the frontals dorsomedially, the posterior ramus extending slightly beyond the external nares. The premaxilla is described as extending even further posteriorly in T. saskatchewanensis (JiménezHuidobro et al., 2018). 
A

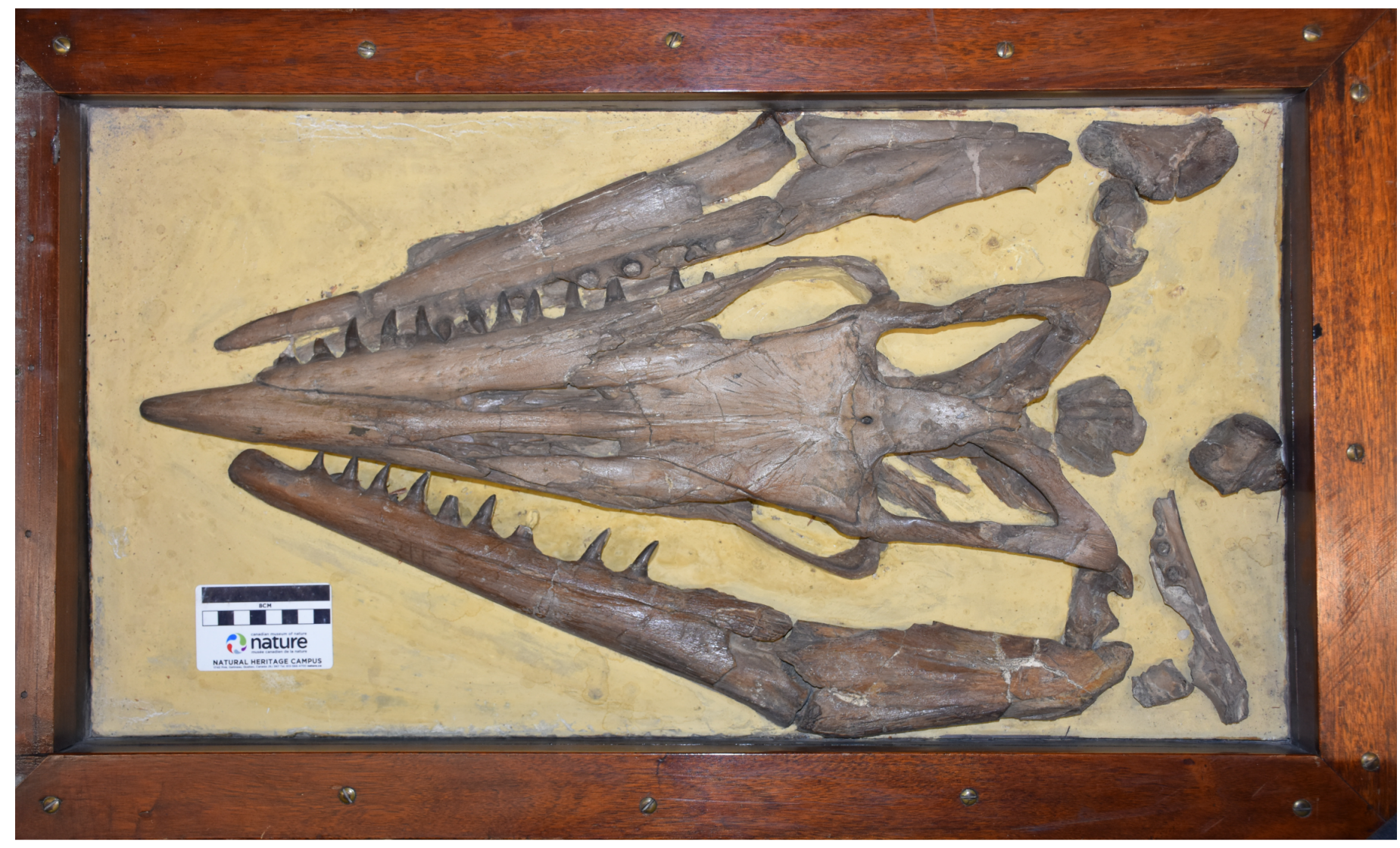

B

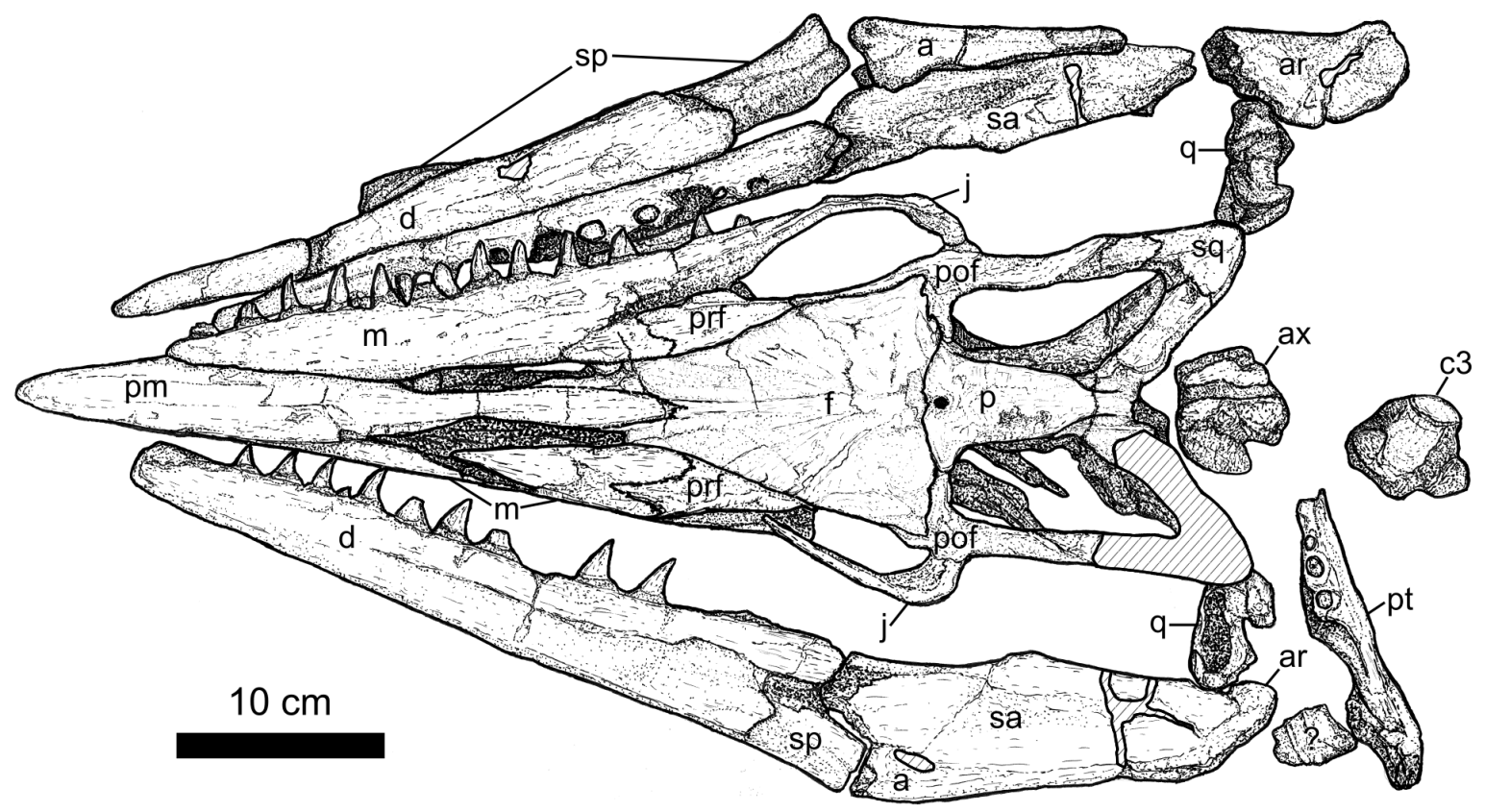

Figure 1. The immature skull of Tylosaurus proriger (CMN 8162). A, photograph of panel mount (scale bar equals $8 \mathrm{~cm}$ ); $B$, interpretive line drawing. Hatching indicates restored areas. 


\section{Maxilla}

The maxillae (Fig. 1) have suffered some damage due to compression, but are otherwise complete. The right maxilla is rotated out of plane so that only its lateral face is exposed. The maxilla is obtusely triangular in outline. Ventrally, it bears 13 teeth, characteristic of Tylosaurus (Russell 1967; Jiménez-Huidobro et al. 2018). The maxillary contact with the premaxilla slopes posterodorsally, terminating at the anterior margin of the naris, which occurs above the fourth maxillary tooth on the better preserved left side (the anterior margin of the naris occurs above the fifth tooth on the right side, where the naris is artificially abbreviated owing to post-mortem rotation of the maxilla). This location of the anterior margin of the naris is typical of Tylosaurus proriger (e.g., Russell, 1967; Everthart 2005; Jiménez-Huidobro et al. 2018). The lateral surfaces of the maxillae are crushed in places, obscuring some of the nutrient foramina, but there remain several visible on either maxilla. The foramina are oval and shallow like those of the premaxilla, and occur along the length of the maxilla. The maxilla is invaginated posteriorly to receive the prefrontal, which extends beneath the posterior margin of the external naris. Dorsal to this, the maxilla forms a short $(21 \mathrm{~mm})$ contact with the frontal. The tooth-bearing portion of the maxilla gradually tapers posteriorly where it underlaps the jugal, terminating beneath the centre of the orbit.

\section{Frontal}

The paired frontals are fused along the midline to form a single triangular unit (Fig. 1). It is narrowest anteriorly, and most broad above the posterior margin of the orbits. A midline ridge ( $6 \mathrm{~mm}$ tall), flanked on either side by a shallow depression, occurs dorsally along the anterior twothirds of the frontal unit. The morphology of the midline ridge and the exclusion of the frontal from the orbital margin were once considered diagnostic of Tylosaurus (Russell 1967), but have since been noted in Halisaurus, Ectenosaurus, and others (Bell 1997; Caldwell and Palci 2007). The midline ridge is not as strongly developed as in T. saskatchewanensis (Jiménez-Huidobro et al. 2018). The frontal is invaded by, and interdigitates with, the premaxilla anteromedially, and overlaps the prefrontal and postorbitofrontal laterally. The frontal forms the posteromedial margin of the naris, but does not appear to extend as far anteriorly as it does in T. saskatchewanensis (Jiménez-Huidobro et al. 2018). Posteriorly, the frontal suture with the parietal is weakly interdigitated nearest the midline. The dorsal surface of the frontal unit is scoured by many elongate $(10-30$ $\mathrm{mm}$ ) sulci that radiate away from the posteromedial edge of the frontal near the parietal foramen.

\section{Prefrontal}

The triangular prefrontal (Fig. 1) forms the anterodorsal border of the orbit. It is sharply pointed anteriorly where it invades the posterior margin of the maxilla; the suture between these two elements is nearly obliterated externally, visible only as a change in the surficial bone texture. The prefrontal bears the overlapping frontal along its supraorbital wing, which forms a weak lateral shelf anteriorly, tapering posteriorly to abut the anterior process of the postorbitofrontal above the anterior third of the orbit. The smooth lateral face of the prefrontal tapers ventrally where it presumably abuts the lacrimal, which is not visible due to crushing of the specimen.

\section{Postorbitofrontal}

The thin anterior process of the postorbitofrontal forms the posterodorsal margin of the orbit (Fig. 1). It broadly underlaps the frontal, extending anteriorly to meet the prefrontal; however, it does not extend beyond the anterior margin of the orbit as it does in T. saskatchewanensis (Jiménez-Huidobro et al. 2018). The short, robust medial process braces the posterior limit of the frontal and contacts the parietal medially where the two bones interdigitate. The short ventral process of the postorbitofrontal overlaps the jugal. Jiménez-Huidobro and Caldwell (2016) note that this process projects further laterally in $T$. bernardi than in T. proriger, but crushing of CMN 8162 prevents us from verifying this.

The posterior process of the postorbitofrontal is the longest of the four, extending as far back as the posterior margin of the supratemporal fenestra. In cross-section, the process is dorsoventrally tall anteriorly, but twists along its ventral contact with the squamosal so that the long axis is oriented mediolaterally. The posterior process is particularly thin where it overlaps the squamosal.

\section{Jugal}

Postmortem compression has caused the jugals to project laterally from the skull (Fig. 1). Despite this, they retain their basic shape. The jugal appears as a slender $\mathrm{C}$-shaped bone that forms the posteroventral margin of the orbit. The dorsal and anterior rami diverge at an angle of 74 degrees. As restored, the anterior ramus on each side is quite short, not extending beyond the anterior margin of the orbit. However, a long, shallow groove extending along the posterolateral surface of the maxilla likely marks the attachment surface for the jugal, in which case the anterior ramus of the jugal originally would have been considerably longer, extending beyond the anterior margin of the orbit as in other mosasaurs (Russell, 1967). The jugal is thickened posteroventrally, but lacks the distinct posteroventral process seen in adult T. kansasensis, T. nepaeolicus (JiménezHuidobro et al. 2016), and T. bernardi (Jiménez-Huidobro and Caldwell 2016). The dorsal ramus of the jugal underlaps the postorbitofrontal, but the precise nature of this 
contact is difficult to discern due to crushing. Although the dorsal ramus of the right jugal is quite slender, the same portion of the left element appears much thicker, as in $T$. bernardi (Jiménez-Huidobro and Caldwell, 2016).

\section{Squamosal}

The V-shaped squamosal borders the supratemporal fenestra posterolaterally and the lower temporal fenestra posterodorsally (Fig. 1). It is thickest at its posterolateral corner, forming the shape of an arrowhead (Russell, 1967). The squamosal branches to underlap the postorbitofrontal anteriorly along a flat, extensive (60 mm long) contact, and the parietal medially along a similarly flat but shorter (30 $\mathrm{mm}$ long) contact. The posterolateral corner of the squamosal is subtly concave ventrally, indicating the position of the quadrate articular facet.

\section{Parietal}

The parietal flares laterally where it abuts the frontal along an anteriorly arched contact (Fig. 1). In CMN 51258, the contact is horizontally foliated to interdigitate with the frontal (Fig. 2). A $6 \times 4 \mathrm{~mm}$ oval parietal foramen occurs immediately adjacent to the frontal contact in CMN 8162, as in Tylosaurus proriger (Russell, 1967:fig. 93), T. bernardi (Lingham-Soliar, 1992; Jiménez-Huidobro and Caldwell,
2016), and T. kansasensis (Everhart, 2005:fig. 5), but not T. nepaeolicus (Russell, 1967:fig. 93) where the foramen is smaller and occurs several $\mathrm{mm}$ from the frontal contact. The foramen is narrowly open anteriorly in both CMN 8162 and CMN 51258 so that the frontal contributes a small amount $(<1 \mathrm{~mm})$ to the margin of the foramen, unlike in larger specimens (e.g., YPM 3990) where the foramen is completely enclosed by the parietal. The parietal table swells laterally where it overhangs the supratemporal fenestra, as in T. proriger (Russell 1967:fig. 93) and T. kansasensis (Everhart 2005:fig. 5), and in contrast to the subparallel lateral margins of the table in T. nepaeolicus (Russell 1967:fig. 93) and T. bernardi (Jiménez-Huidobro and Caldwell 2016:fig. 3). The fossae for the cervical epaxial musculature on the posterodorsal surface of the parietal are well-developed, covering 38\% of the length of the anteroposterior parietal table. This condition is common to T. proriger and in contrast to T. kansasensis (29\%) and especially T. nepaeolicus (17\%). The narrow suspensorial rami posteriorly diverge from one another at an angle of 99 degrees, which is more acute than the 127 degrees observed in the larger T. proriger AMNH 4909 (Russell 1967:fig. 92). A low, rounded posteromedial projection occurs on each suspensorial ramus, bounding the epaxial
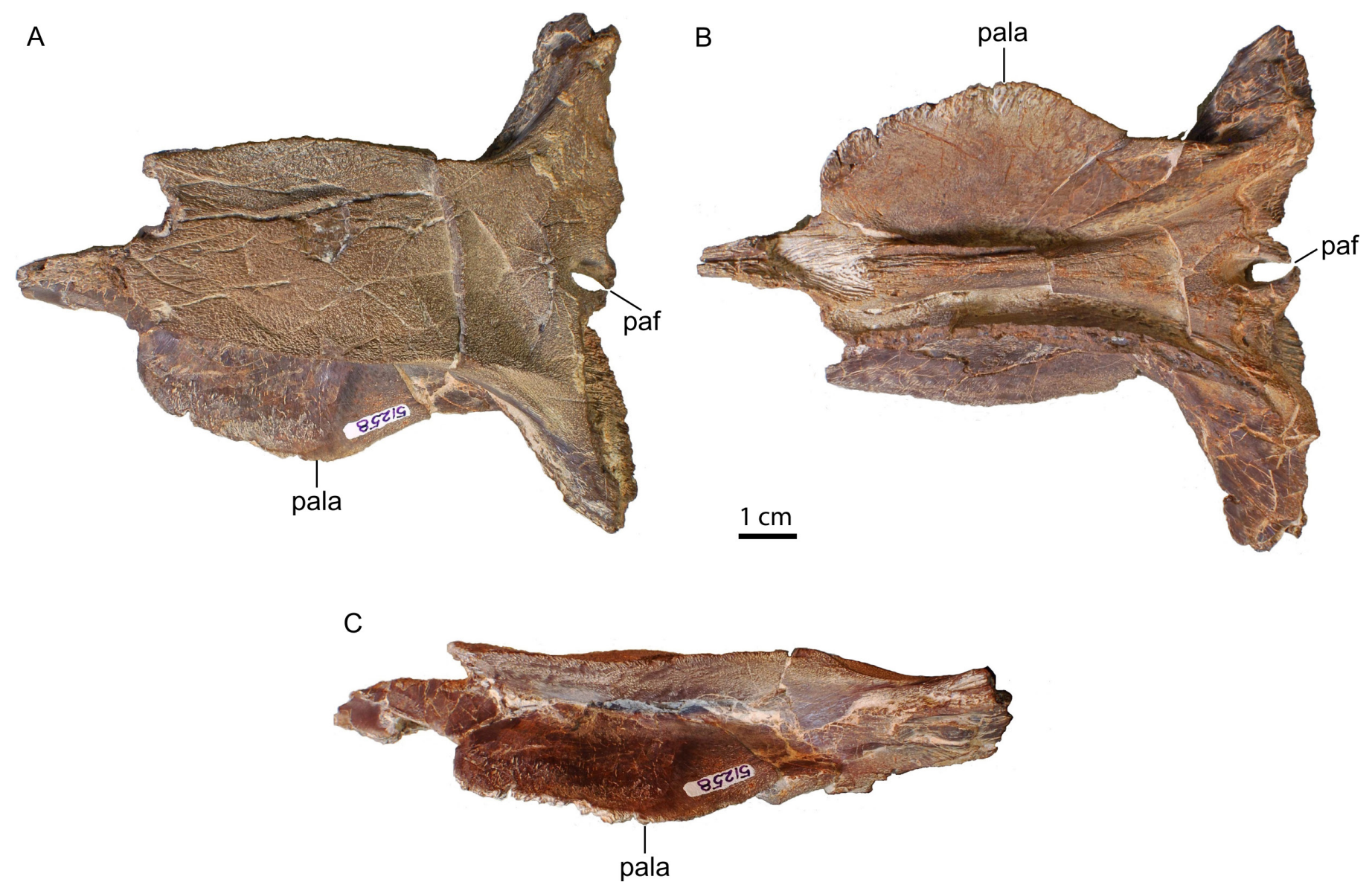

Figure 2. Parietal of immature Tylosaurus proriger ( $C M N$ 51258). A, dorsal view; B, ventral view; C, right lateral view. 
muscle scars posterolaterally. The ventral surface of the parietal is inaccessible in CMN 8162, but visible in CMN 51258 (Fig. 2B). The specimen is damaged so that the left parietal ala is missing. The thin, crescentic right ala projects ventrolaterally and spans the length of the dorsal parietal table. A midline ridge, flanked on either side by a shallow sulcus, occurs on the ventral surface of the parietal between the descending alae, a condition apparently characteristic of Tylosaurus (Russell, 1967). A shallow, median concavity occurs between the midline ridge and the parietal foramen, as in Platecarpus and Tylosaurus (Russell 1967).

\section{Basioccipital}

The basioccipital-basisphenoid complex (CMN 51259; Fig. 3) reportedly measures $113 \mathrm{~mm}$ in length (Lyons et al, 2000). It appears somewhat dorsoventrally crushed. The semicircular occipital condyle of the basioccipital is affixed to the body of the element via a slightly constricted neck. It is not as distinctly reniform as figured for Platecarpus tympaniticus (Russell 1967:fig. 17; Konishi et al. 2010:fig. 4) or Plioplatecarpus spp. (Holmes 1996:fig. 3; Cuthbertson and Holmes 2015:fig. 10), although this may be an artifact of crushing. The dorsolateral surfaces of the basioccipital are faceted at an oblique angle to support the exoccipitals from below. Immediately anterior to the occipital condyle, a pair of basal tubera project ventrolaterally. These appear flatter than in either of the aforementioned taxa and, particularly in the case of Platecarpus tympaniticus, do not project as far laterally. Several small nutrient foramina occur between the basal tubera ventrally. The floor of the medullary cavity excavates the dorsal surface of the basioccipital along the midline. The cavity is narrow anteriorly, widens near the middle of the element (concomitant with the expansion of the medulla), then narrows again posteriorly at the neck of the occipital condyle before widening again at the foramen magnum. The cavity appears slightly narrower overall than in P. tympaniticus (Russell 1967:fig. 10) and does not bear the same large opening for the basilar artery posteriorly. Russell (1967) describes the floor of the basioccipital medullary cavity in Tylosaurus as being floored by a thin sheet of bone from the basisphenoid, but this is not visible on the available 3D model or photographs. Lateral to the medullary cavity, between the occipital condyle and basal tubera, round, roughened surfaces mark the contacts for the overlapping opisthotic.

\section{Basisphenoid}

The basisphenoid of CMN 51259 (Fig. 3) is narrow compared to that of Platecarpus tympaniticus (Russell 1967:fig. 10) or Plioplatecarpus peckensis (Cuthbertson et al. 2015:fig. 3F), more nearly approximating a triangle in dorsal view than a square, as described by Russell (1967) for Clidastes. The dorsal midline of the element is excavated
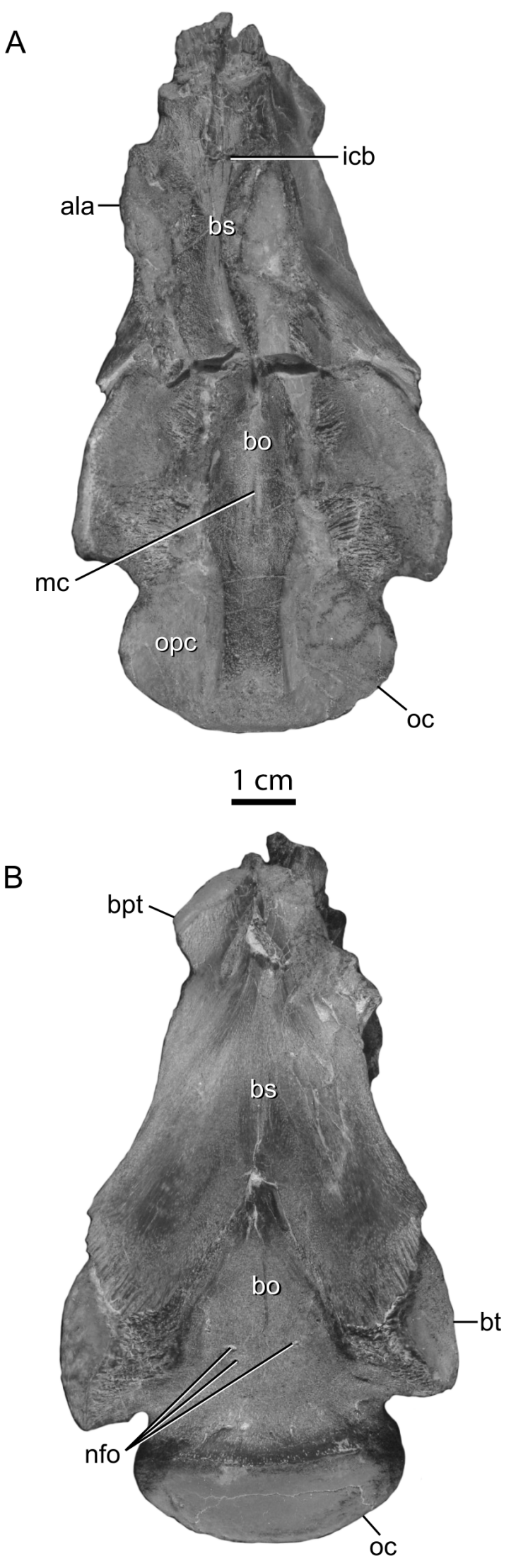

Figure 3. Fused basioccipital-basisphenoid of immature Tylosaurus proriger (CMN 51259). A, dorsal view; B, ventral view. 
by the medullary cavity, which is continuous with that of the basioccipital. The cavity is expanded anteriorly, near the broken parasphenoid (cultriform) process. Poor resolution of the 3D model does not allow for the identification of the small foramina that typically perforate this region, although Lyons et al. (2000:fig. 8) labeled the openings for the internal carotid artery and abducens nerve (VI) in their expected positions (Russell 1967:fig. 10). Posteriorly, on each side of the medullary cavity, a pair of short, thin alar processes project dorsally, although not to the extent seen in Platecarpus tympaniticus (Russell 1967:fig. 9). A roughened, bony overhang projects lateral to the alar process, beneath which the vidian canal opens posteriorly. The lateral walls of the basisphenoid are smooth and concave, possibly facilitating the passage of the vena capitits lateralis (Russell 1967). Ventrally, a pair of tongue-like processes diverge posterolaterally to brace the basal tubera from beneath. These appear to more fully envelop the basal tubera than in either $P$.

A

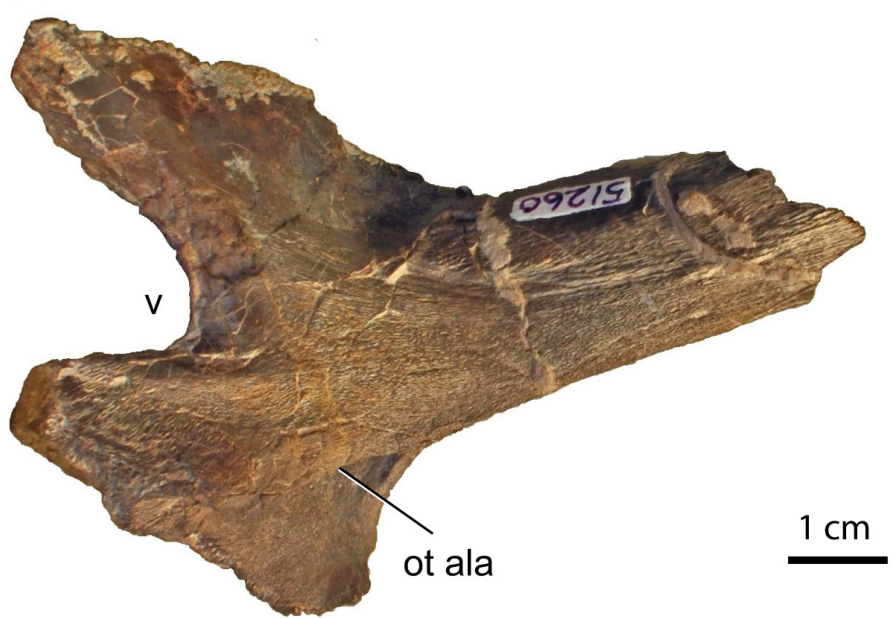

C

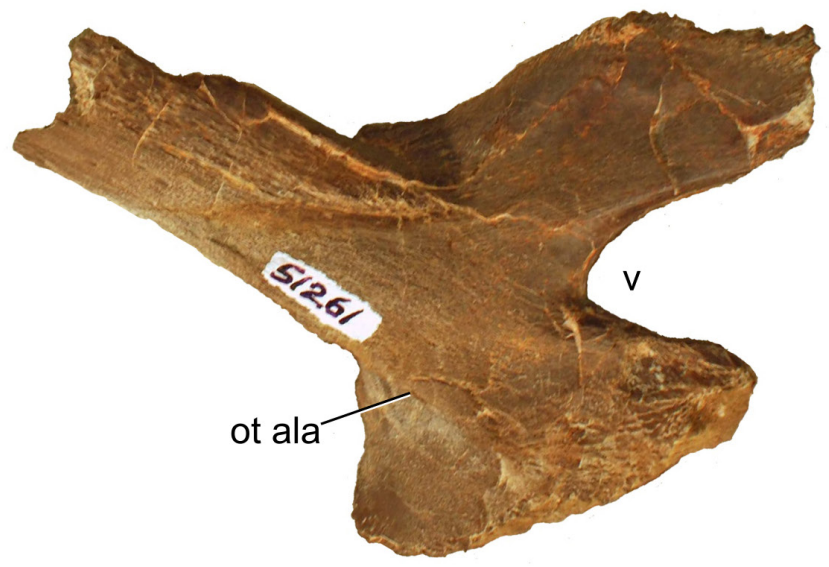

tympaniticus (Russell 1967:fig. 9) or Plioplatecarpus spp. (Holmes 1996:fig. 3; Cuthbertson and Holmes 2015:fig. 12). Further anteriorly, the paired basipterygoid processes project anteroventrally. They are considerably smaller than Platecarpus tympaniticus (Russell 1967:figs. 9,10), and more closely resemble those of Plioplatecarpus primaevus in size (Holmes 1996:fig. 6).

\section{Prootic}

The triradiate prootics are inaccessible in CMN 8162, yet intact in CMN 51260 (left) and CMN 51261 (right) (Fig. 4). The anteroventral process expands as it descends to meet the alar process of the basisphenoid along an anteroposteriorly broad and oblique butt joint with weakly crenulated margins. The process closely resembles that of Clidastes propython (Russell 1967:fig. 12), but the anterodorsal border is not flexed near the exit for cranial nerve $\mathrm{V}$ as in the latter taxon. It is also relatively short
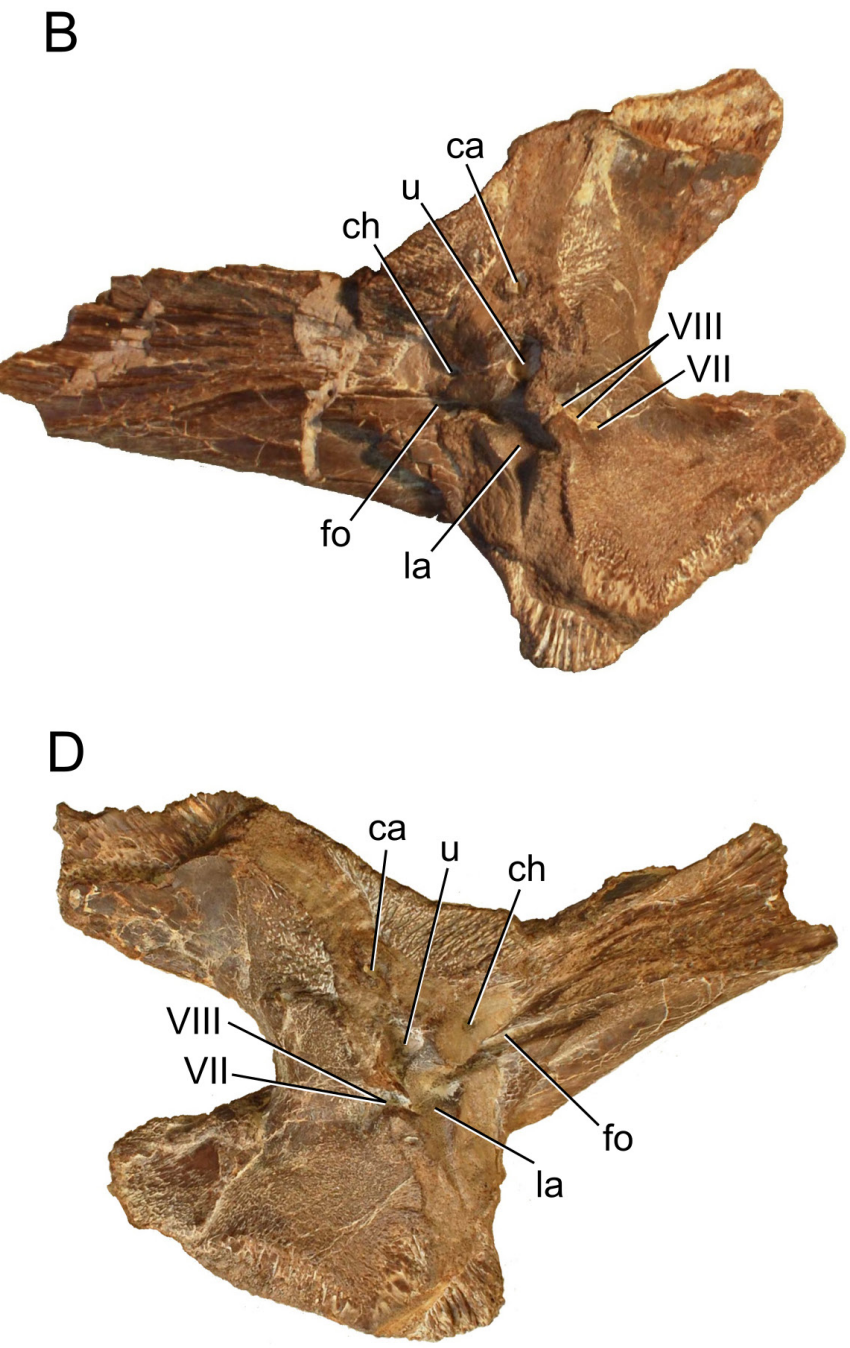

Figure 4. Left (CMN 51260) and right (CMN 51261) prootics of immature Tylosaurus proriger. Left prootic in lateral ( $A$ ) and medial (B) views; right prootic in lateral (C) and medial (D) views. 
compared to that of Plioplatecarpus peckensis (Cuthbertson et al. 2015:fig. 3C). The anterodorsal process is likewise broad and notched anteromedially to support the parietal from below. A broad, flat contact surface descends posteroventrally from the parietal contact on the medial surface of the anterodorsal process, forming a butt joint with the overlying supraoccipital. The bone on each side of this flattened surface is lineated to interdigitate with corresponding surfaces on the supraoccipital. At the V-shaped juncture of the anterodorsal and posterodorsal processes, near the supraoccipital contact, the incisure is not as well defined as in C. propython (Russell, 1967:fig. 12), yet its development is variable between the left (CMN 51260) and right (CMN 51261) sides. The posterodorsal process is unremarkable, and ascends to the level of the anterodorsal process to interdigitate with the supratemporal. Medially, the posterodorsal process is concave and strongly lineated, indicating a tight, interdigitating articulation with the opisthotic. An enlarged otosphenoidal ala occurs on the lateral surface of the prootic, spanning the combined length of the anteroventral and posterodorsal processes. It completely covers the exit for cranial nerve VII laterally, typical of Tylosaurus (Russell 1967).

Internally, the morphology of the prootic does not differ appreciably from that of other mosasaurids (Russell 1967; Cuthbertson et al. 2015). The opening for the utricle is located on the flattened contact for the supraoccipital, where the two bones intersect with the posteriorly occurring opisthotic. A smaller opening for the anterior vertical semicircular canal occurs on the same flattened surface, anterodorsal to the utricular opening. A second small opening for the horizontal semicircular canal is located posterodorsally an equal distance away from the utricular opening. Immediately beneath the utricular opening, a deep fossa houses the exits for cranial nerves VII and VIII. A thin, bony wall separates this fossa from the opening for the labyrinth posteriorly. The opening for the labyrinth is $\mathrm{V}$-shaped in outline and narrows posterodorsally towards the fenestra ovalis.

\section{Supraoccipital}

The isolated supraoccipital (CMN 51263) is shaped like a gable roof, although crushing and dorsoventral shearing about the sagittal plane has obscured its original morphology (Fig. 5). There is evidently a pronounced sagittal crest that spans the dorsal midline as in most other mosasaurs (Russell, 1967). The midline crest gives way posteroventrally to a pair of striated, ventrally facing surfaces that interface with the opisthotics. This striated texture continues about the ventrolateral lip of the supraoccipital and, together with a semicircular lobe of bone opposite the otic capsule anteroventrally, fits into corresponding contacts

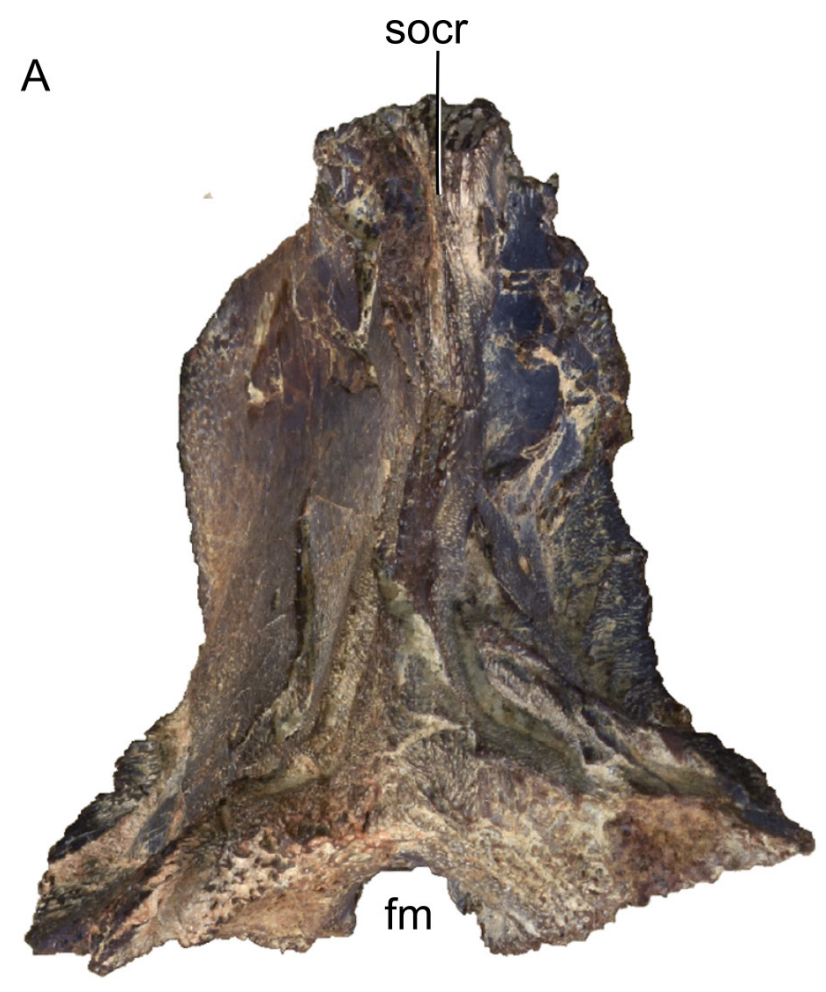

$1 \mathrm{~cm}$

B

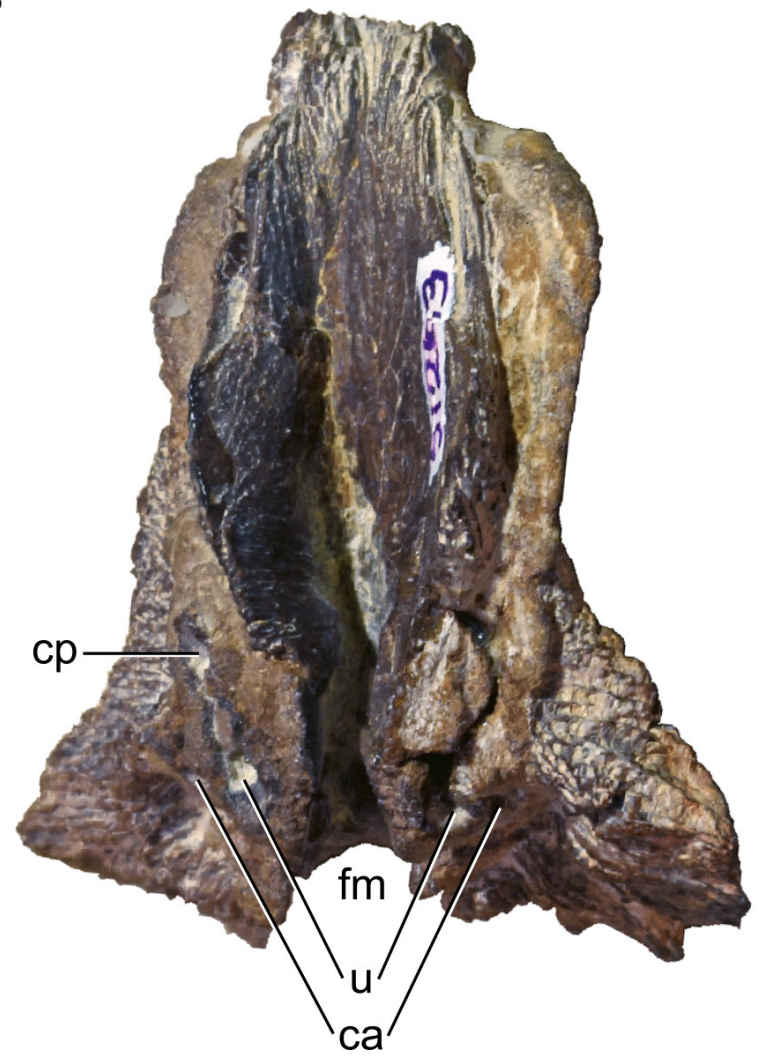

Figure 5. Supraoccipital of immature Tylosaurus proriger (CMN 51263). A, anterior view; B, posterior view. 
on the prootic. Within the walls of the otic capsule, the openings for the utricle and semicircular canals are visible, which correspond to their counterparts on the prootic. Ventrally, the supraoccipital is excavated along the midline to cover the posterior brain stem.

\section{Pterygoid}

A disarticulated, right pterygoid is preserved behind the skull of CMN 8162, with the ventral surface exposed (Fig. 1). Most of the tooth-bearing body, ectopterygoid process, and quadrate ramus are missing. The roots of three anterior pterygoid teeth and two additional alveoli are visible, but the posterior-most tooth row is missing. The teeth are circular to oval in cross-section, with the long axis oriented parallel to that of the tooth row. A smooth, shallow groove runs lengthwise lateral to the preserved tooth row, producing a shelf $7 \mathrm{~mm}$ wide. What little remains of the base of the ectopterygoid process suggests that, when complete, the process projected medially as in Tylosaurus proriger AMNH 4909 (Russell 1967:fig. 21), and was not angled anteromedially as in Platecarpus tympaniticus and Clidastes propython (Russell 1967:fig. 22).

\section{Quadrate}

The quadrates of CMN 8162 are only visible in lateral view (Fig. 1). Each element is vaguely $\mathrm{C}$-shaped, opening posteriorly. The descending suprastapedial process is short and does not extend beyond mid-height, unlike in the larger Tylosaurus proriger YMP 3990 and AMNH 4909 (Russell, 1967:fig. 94). The tympanic alae are broken in CMN 8162, but the isolated right quadrate (CMN 51262) reveals that the ala was quite thin and encapsulated a moderately deep $(15 \mathrm{~mm}$ ) tympanic cavity (Fig. 6). The ala descends the posterolateral margin of the squamosal to nearly reach the robust mandibular condyle ventrally before curling anterodorsally towards the infrastapedial process, as in T. proriger (Russell 1967). The infrastapedial process is modestly developed, projecting posteriorly. In CMN 8162, the process is acutely defined, resembling the condition of some T. proriger (e.g., AMNH 1555) but not others (e.g., CMN 51262, YPM 3990, AMNH 4909, RMM 5610). The infrastapedial process is larger than in either T. nepaeolicus (YPM 3970, YPM 3992) or T. kansasensis (Everhart 2005:fig. 3). CMN 51262 bears an ellipsoidal (sometimes described as rectangular in Tylosaurus; e.g., JiménezHuidobro and Caldwell 2016) stapedial pit on its medial surface, near the anterodorsal corner of the meatus. The quadrate condyles are visible in CMN 51262 (Fig. $6 \mathrm{C}, \mathrm{D})$. The dorsal condyle is smooth and vaguely crescentic, opening posteromedially. The stout anterior lobe of the crescent contrasts with the elongate, laterally concave lobe posteriorly. The ventral condyle is likewise smooth and vaguely crescentic, opening anteromedially. The anterior

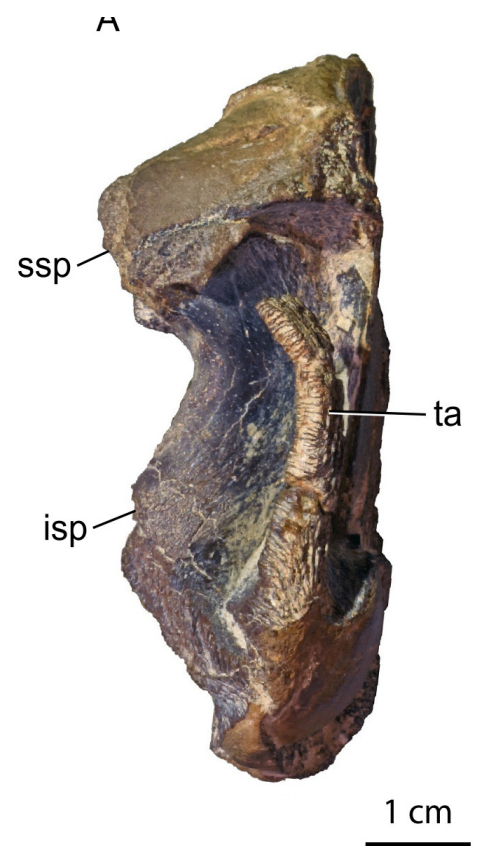

D

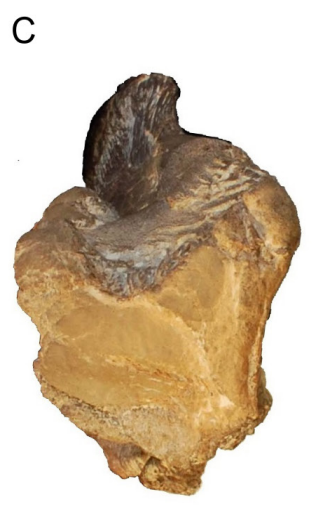

D

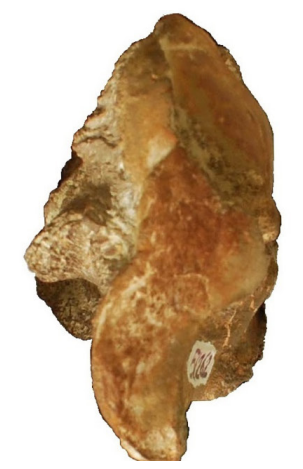

Figure 6. Right quadrate of immature Tylosaurus proriger (CMN 51262). A, lateral view; B, medial view; C, dorsal view; $D$, ventral view.

lobe is bulbous and has a larger surface area than the posterior lobe, which is posterolaterally concave.

\section{Dentary}

The articulated lower jaws of CMN 8162 are visible in lateral view (Fig. 1). The elongate dentary is very slender relative to those of adult Tylosaurus proriger, being 6.6 times longer than posteriorly tall (compared to 4.5 times longer than tall in adults). Anteriorly, the dentary tapers $41 \mathrm{~mm}$ in advance of the first tooth to terminate in a blunt and edentulous rostrum characteristic of Tylosaurus (JiménezHuidobro et al. 2016). Nine teeth occur in the better preserved left dentary, but the additional alveoli indicate a total tooth count of 13 . An anteroposteriorly trending row of shallow nutrient foramina, set within a shallow trough, is present laterally on the posterior three quarters of the dentary. True of all mosasaurs (Russell, 1967), the dentary is only loosely connected to the postdentary bones, forming a mobile intramandibular joint. 


\section{Splenial}

The elongate splenial of CMN 8162 spans the posterior two-thirds of the dentary, which overlies the splenial laterally, obscuring much of its shape (Fig. 1). Nevertheless, the splenial is not as visibly expanded dorsoventrally as in Platecarpus tympaniticus (AMNH 1821; Russell 1967:fig. 29). It appears dorsoventrally thickened posteriorly. The splenial angles ventrally at its posteriormost extent where it abuts the angular, the contact for which is weakly concave and oval in outline.

\section{Angular}

The long and slender angular of CMN 8162 is gently bowed ventrally where it curves along the length of the overlapping surangular (Fig. 1). It is dorsoventrally expanded anteriorly and an anteroventral swelling of the element evidently corresponds to a concavity on the posterior end of the splenial. Posteriorly, the angular gradually tapers to abut the articular, terminating beneath the jaw joint.

\section{Surangular}

The anteroposteriorly elongate surangular of CMN 8162 is rectangular in outline (Fig. 1). The anterior contact for the dentary is bluntly pointed and bears a shallow fossa laterally to receive the tooth-bearing portion of the dentary in a loosely articulating joint. The anterodorsal margin of the surangular is concave to support the coronoid, which is missing from both sides of the skull. Based on the size of the concavity, the coronoid appears to have been relatively as large as in mature Tylosaurus proriger (Russell 1967:fig. 95). A pair of shallow, lateral grooves run the length of the surangular, converging posteriorly beneath the jaw joint. The dorsal surface of the surangular is slightly concave posteriorly where it forms the anterior two-thirds of the jaw joint.

\section{Articular}

The articular of CMN 8162 is ventrally sinusoidal, continuous with the external curvature of the angular (Fig. 1). It is tightly appressed to the posterior margin of the surangular and forms the posterior third of the mandibular cotyle. The articular increases in dorsoventral height posteriorly, terminating in a dorsally rounded retroarticular process. This process, better preserved on the right side, is deflected posteroventrally.

\section{Marginal dentition}

Several of the marginal teeth of CMN 8162 appear to be at least partially reconstructed in plaster. Where the original teeth are visible, they are homodont; the maxillary teeth are practically indistinguishable from those of the dentary (the premaxillary teeth are partly buried in plaster) (Fig. 1). The teeth are tallest (up to $22 \mathrm{~mm}$ long) near the middle of the tooth row and shorten toward each end. Each ziphodont tooth crown is gently curved posteriorly. Slight carinae, apparently lacking denticles, are present anteriorly and posteriorly. The labial enameled crown surface is weakly ridged (the lingual surfaces are obscured by plaster supports). The teeth are quite slender and appear more laterally compressed compared to large Tylosaurus specimens (Russell 1967), being more lenticular than D-shaped in cross-section. The tooth root is swollen and composed of roughened cementum (Caldwell et al. 2003).

\section{RESULTS}

The ANCOVA results are presented in Table 1. CMN 8162 plots on the same regression line for each of the seven skull variables examined; its inclusion does not significantly alter the allometric trend lines of Tylosaurus proriger. The results of the RMA regression analysis are presented in Figure 7 and Table 2. Representation of different size categories across each variable is generally quite good, with specimens spread out approximately evenly along the regression lines. There are, however, notable clusters of specimens around log basal skull length (BSL) values of approximately 2.78 and $3.00(\mathrm{BSL}=600 \mathrm{~mm}$ and 1,000 $\mathrm{mm}$, respectively).

Isometry cannot be rejected for five of the seven variables considered here. This is unsurprising, given that their slopes approximate a value of 1 , and first-hand observation of the specimens reveals that the smaller ones do not obviously differ in shape from the larger ones. The length of the premaxillary rostrum is negatively allometric, signifying its slower growth rate relative to the rest of the skull. Quadrate height is positively allometric, indicative of its relatively rapid growth rate. Correlation of all the variables with basal skull length is highly significant (Table 2).

\section{DISCUSSION}

CMN 8162 can be positively attributed to Tylosaurus based on the presence of a prefrontal that does not contribute to the margin of the external naris, a frontal that is excluded from the margin of the orbit by the prefrontal and postorbitofrontal, an edentulous rostral 'prow', and 13 maxillary and dentary teeth each (Jiménez-Huidobro et al. 2018). It can be further assigned to $T$. proriger based on the position of the anterior margin of the naris above the fourth maxillary tooth, a pineal foramen that is adjacent to the frontoparietal suture, a parietal with an extensive insertional area for the epaxial musculature, and a tympanic ala of the quadrate that descends to nearly the level of the jaw joint before terminating beneath the infrastapedial process (Russell 1967; Jiménez-Huidobro and Caldwell 2016). The second skull (CMN 51258-51263) is attributable to T. proriger based on its overall similarity to CMN 8162, a 
Table 1. Results for the one-way analysis of covariance, including and excluding CMN 8162 from the growth trajectory of Tylosaurus proriger.

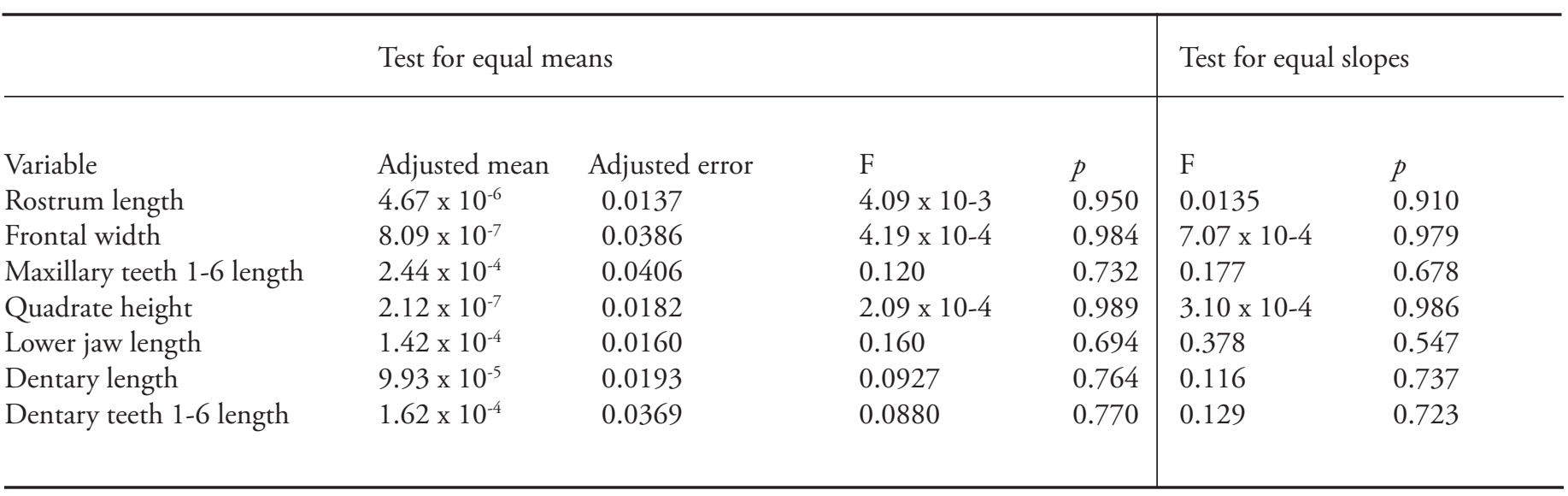

Table 2. Reduced major axis regression results. * denotes allometry. ** denotes statistical significance

\begin{tabular}{|c|c|c|c|c|}
\hline Variable & RMA equation & Confidence interval of slope & $\mathrm{r}$ & Correlation $p$ (permuted) \\
\hline Rostrum length & $y=0.533 x+0.152$ & $0.246,0.666^{*}$ & 0.890 & $0.0024^{* *}$ \\
\hline Frontal width & $y=1.124 x-1.064$ & $0.985,1.27$ & 0.963 & $0.0001^{* *}$ \\
\hline Maxillary teeth 1-6 length & $y=0.982 x-0.546$ & $0.752,1.16$ & 0.941 & $0.0001^{* *}$ \\
\hline Quadrate height & $y=1.22 x-1.52$ & $1.04,1.41^{*}$ & 0.985 & $0.0001^{* *}$ \\
\hline Lower jaw length & $y=1.08 x-0.191$ & $0.945,1.26$ & 0.975 & $0.0001^{* *}$ \\
\hline Dentary length & $y=0.881 x+0.168$ & $0.736,1.02$ & 0.965 & $0.0002^{* *}$ \\
\hline Dentary teeth 1-6 length & $y=0.830 x-0.119$ & $0.687,1.05$ & 0.927 & $0.0001^{* *}$ \\
\hline
\end{tabular}

Figure 7. Growth in the skull of Tylosaurus proriger. Biplot shows results of reduced major axis regression. Growth in the length of the edentulous rostrum is negatively allometric; growth in the height of the quadrate is positively allometric.

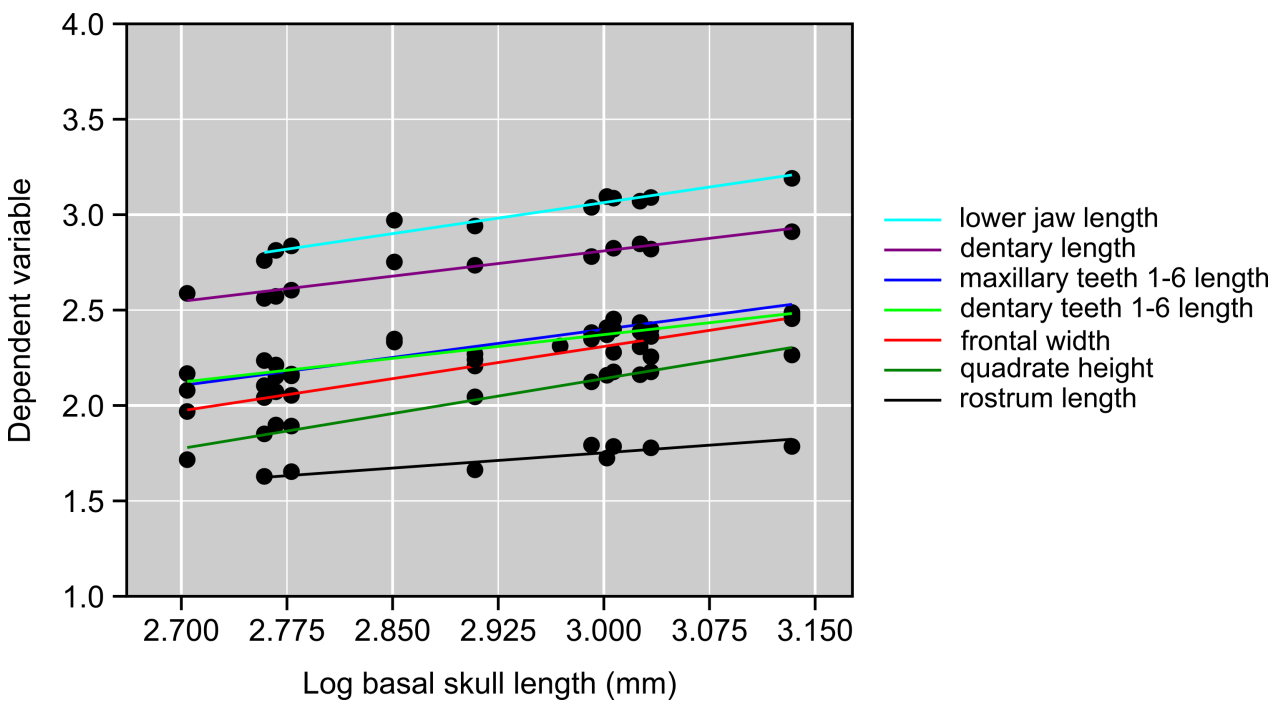


pineal foramen that is adjacent to the frontoparietal suture, and the lateral concealment of the exit for cranial nerve VII by the otosphenoidal ala of the prootic (Russell 1967). This assignment is in further agreement with the provenance and stratigraphic position of the two skulls (see Materials and Methods above).

Although the small size of two skulls is suggestive of their immaturity, size is not a particularly reliable indicator of age (Hone et al. 2016). However, the ANCOVA results further support the identity of CMN 8162 as a subadult $T$. proriger because the specimen falls on the same allometric trend lines. Given the great similarity of the second individual described here (CMN 5125851263) to CMN 8162, we likewise consider it an equivalent ontogimorph of $T$. proriger.

Despite three centuries of collecting and research, this is the first quantitative investigation of cranial allometry in mosasaurs. Our dataset is inexhaustive, largely reflecting the fact that $T$. proriger material is widespread across the globe (thanks to early trading between museums), and difficult to study thoroughly with limited resources. As such, most instances of isometry reported here are simply an outcome of small sample size, a phenomenon termed 'soft isometry' by Brown and Vavrek (2015).

In view of these considerations, how might we expect the skull of $T$. proriger to change shape with growth? Some insight might be gained through consideration of their purported closest living relatives, snakes and varanids (Lee 1997; Conrad 2008). In the banded watersnake (Nerodia fasciata), frontal width and maxilla length are isometric, and quadrate length (= height in this study) and mandible length are positively allometric (Hampton 2014). Growth in other skull variables is also significantly allometric, but these have no equivalent in this study.

Unfortunately, ontogenetic allometry of the skull has not been documented in varanids, but phylogenetic allometry (sensu Gould 1966) has been (Emerson and Bramble 1993; Openshaw and Keogh 2014; Openshaw et al. 2016). Thus, in the genus Varanus, which varies appreciably in size, tooth row length is isometric, whereas skull width and jaw length are positively isometric (Emerson and Bramble 1993). Again, other skull measurements are purportedly significantly allometric, but have no equivalent here. Notably, the dataset of Emerson and Bramble (1993) is small $(\mathrm{n}=9)$, and so likely includes instances of 'soft isometry.'

With skull allometry in snakes and varanids as context, it is unsurprising that quadrate height in T. proriger should scale positively allometrically, as it does in $N$. fasciata. This likely would have correlated with increased skull height in larger (and, presumably, older) individuals, and facilitated greater bite forces (Herrel and O'Reilly 2005). It is also a predictable result of endochondral ossification (de Beer 1985). On the other hand, lower jaw length is positively allometric in snakes and varanids, yet isometric in T. proriger. This unexpected outcome may simply be another example of 'soft isometry' in T. proriger, although Emerson and Bramble (1993) rejected isometry in Varanus based on an even smaller sample size. That the edentulous rostrum ('prow' sensu Russell, 1967) of T. proriger should be negatively allometric is also surprising because JiménezHuidobro et al. (2016) argued that the opposite phenomenon occurs in T. nepaeolicus, noting that the largest individuals have the longest rostra; however, their argument was not quantified. Thurmond (1969) used linear regression to reason that there is no significant change in rostral morphology in Tylosaurus, but his dataset was less exhaustive. Russell (1967:68) suggested that the edentulous rostrum might be used "to stun prey or defend the mosasaur against enemies (sharks)", which aligns rather nicely with our findings. Smaller individuals would have had a greater need for such a structure to stun prey, as the large adults could likely often swallow prey whole. Similarly, young $T$. proriger may have been more apt to use the rostrum in defense; it seems the largest individuals were mostly without predators (other than conspecifics) (Everhart 2008).

We also note a few other ontogenetic differences in $T$. proriger that do not stem from our allometric analysis. The premaxillary foramina evidently increase in size (but not obviously in number) with age, which may have allowed for increased innervation and blood flow to the enlarged snout. The anterior margin of the parietal foramen becomes completely enclosed within the parietal, presumably a simple result of the complete ossification of the parietal. Finally, the marginal dentition changes from being labiolingually compressed in young individuals to more nearly conical in older individuals. A similar trend in tooth inflation has been noted in some other mosasaurs (e.g., Gilmore 1927), and even tyrannosaurid dinosaurs (Carr 1999). This change may have signaled an ecological shift from a hitand-run style of predation where quick, slashing wounds were inflicted on the prey, to a grappling style of predation where the prey was held firmly within the jaws by the robust teeth. More investigation into ontogenetic shifts of mosasaur feeding habits is clearly warranted.

Finally, we consider our findings as they apply to the recent controversy regarding the validity of $T$. kansasensis. Everhart (2005) noted several cranial characters that serve to distinguish T. kansasensis, including: (1) large premaxillary rostral foramina; (2) a short, round pre-dental process (edentulous rostrum) of the premaxilla; (3) a thick quadrate ala; (4) a shallow quadrate conch (alar cavity); (5) a quadrate lacking an infrastapedial process; (6) a pineal foramen adjacent to or invading the frontoparietal suture; (7) frontal medial sutural flanges that extend onto the parietal; (8) a 
keel on the dorsal midline of the frontal; (9) a 90 degree posteroventral angle of the jugal. Jiménez-Huidobro et al. (2016) argued that most of these characters are ontogenetically variable in other mosasaurs, and that the smaller $T$. kansasensis is therefore a junior synonym of T. nepaeolicus, its larger contemporary (both of which pre-date T. proriger within the Niobrara Formation; Everhart, 2001).

Regarding (1), Jiménez-Huidobro et al. (2016) note that the number and position of the premaxillary foramina is variable among specimens and varies between right and left sides. However, they do not comment on the size of the foramina, which is the relevant character under consideration. In T. proriger, the foramina do not appear to vary in relative size with age.

With respect to (2), Jiménez-Huidobro et al. (2016) maintained that the shorter rostrum of T. kansasensis developed into the relatively longer rostrum of $T$. nepaeolicus, implying positive allometry. As stated above, this inference runs counter to our findings for T. proriger. We agree with Jiménez-Huidobro et al. (2016) that the shape of the anterior margin of the rostrum is intraspefically variable in Tylosaurus, and probably of little diagnostic value.

Although Jiménez-Huidobro et al. (2016) do not explicitly comment on (3), they do note that mosasaur quadrates tend to become stouter throughout ontogeny. If the same applies to the quadrate ala, then we might expect it to thicken with age, which runs contrary to the hypothesis that T. kansasensis (with its thicker quadrate ala) is an immature ontogimorph of T. nepaeolicus. In any case, the quadrate ala does not obviously vary proportionally with size in T. proriger, although we did not quantify this character. We cannot comment on (4) for the same reason. Jiménez-Huidobro et al. (2016) argue that the infrastapedial process of the quadrate (5) is absent in both $T$. kansasensis and T. nepaeolicus. We note that the infrastapedial process is present in both immature and mature T. proriger; its presence does not vary ontogenetically.

Concerning (6), Jiménez-Huidobro et al. (2016) note that the location of the pineal foramen within the parietal is variable in $T$. proriger, and that this character is therefore not suitably diagnostic. However, although we agree that there is some minor variance in the positioning of the foramen in $T$. proriger, that variance pales in comparison to that observed between T. kansasensis and T. nepaeolicus, where the foramen nearly abuts the frontoparietal suture in the former (e.g., FHSM VP-2295), and is a full $36 \mathrm{~mm}$ from the suture in the latter (FHSM VP-2209). The position of the parietal foramen is a commonly used character in mosasaur systematics, and other valid species vary less in this character than noted here (e.g., Cuthbertson et al. 2007). Jiménez-Huidobro et al. (2016) do not comment on (7), so nor do we.
Jiménez-Huidobro et al. (2016) note that the frontal midline keel (8) is more developed in adult Clidastes propython than in juveniles of this species, and that this character is ontogenetically invariable in $T$. proriger (with which we agree). However, they argue that the keel becomes less prominent between the (presumably immature) T. kansasensis and the (presumably mature) T. nepaeolicus. There is no known instance of this being the case in any other mosasaur species, and so we consider their argument with respect to this character special pleading.

Character (9) is difficult to assess, with only a single jugal known for T. nepaeolicus. Jiménez-Huidobro et al. (2016) argue that the vertical and horizontal rami of the jugal form a 90 degree angle in both T. kansasensis and T. proriger, which they convincingly illustrate with examples. However, one feature that has not merited comment from either Everhart (2005) or Jiménez-Huidobro et al. (2016) is that the posteroventral process of the jugal is more ventrally positioned in T. kansasensis than in T. nepaeolicus (JiménezHuidobro et al. 2016:fig. 6). The two taxa might therefore be distinguished on this basis.

Bearing these considerations in mind, we believe that the weight of the evidence supports the distinction between T. kansasensis and T. nepaeolicus; the former is not simply an immature ontogimorph of the latter. The ontogenetic trends observed in T. proriger are inconsistent with the proposed trends for T. nepaeolicus, and in some cases (e.g., development of the rostrum and midline frontal keel) run in completely the opposite direction.

\section{CONCLUSIONS}

Growth in the skull of Tylosaurus proriger appears to have been largely isometric, except as concerns the length of the premaxillary rostrum (negatively allometric) and the height of the quadrate (positively allometric). The parietal foramen also became fully enclosed within the parietal with age, and the marginal dentition became less labiolingually compressed and increasingly conical. These observations have interesting implications for mosasaur ecology and taxonomy, particularly as concerns the recent synonymy of T. kansasensis with T. nepaeolicus.

Despite the importance of accounting for ontogeny when considering the ecology and taxonomy of a group of organisms, this line of research has garnered relatively little attention in the study of Mosasauridae. Ours is the first study to quantify allometry in a mosasaur skull, but further research is clearly needed. Many instances of 'soft isometry' noted here can be rectified via more comprehensive allometric analyses, ideally over a wider range of skull sizes than considered here. Inclusion of a wider diversity of species would also provide much needed phylogenetic 
context regarding questions of "synonymy through ontogeny" (Scannella and Horner 2010). Finally, we stress that this larger allometric project will only be realized through the publication of primary osteological descriptions involving specimens of varying ontogenetic stages, like the one provided here (with the time between discovery and description ideally less than 107 years).

\section{ACKNOWLEDGEMENTS}

We thank M. Currie and K. Shepherd (CMN) for access to specimens, S. Rufolo for his skilled photography and artwork, C. Mehling for measurements provided, and M. Everhart for providing photographs and for reviewing an early version of the manuscript. Thanks also to reviewers R. Cuthbertson and P. Jiménez-Huidobro, and editor R. Holmes for their help improving the manuscript. This study was supported by a Discovery Grant from the Natural Sciences and Engineering Research Council of Canada to JCM.

\section{LITERATURE CITED}

Bell, G. L., Jr. 1997. A phylogenetic revision of North American and Adriatic Mosasauroidea; pp. 293-332 in J. C. Callaway and E. L. Nicholls (eds.). Ancient Marine Reptiles. Academic Press, San Diego.

Brown, C. M., and M. J. Vavrek. 2015. Small sample sizes in the study of ontogenetic allometry; implications for palaeobiology. PeerJ 3:e818. https://doi.org/10.7717/peerj.818.

Caldwell, M. W. 1996. Ontogeny and phylogeny of the mesopodial skeleton in mosasauroid reptiles. Zoological Journal of the Linnean Society 116:407-436.

Caldwell, M. W. 2007. Ontogeny, anatomy and attachment of the dentition in mosasaurs (Mosasauridae: Squamata). Zoological Journal of the Linnean Society 149:687-700.

Caldwell, M. W., and A. Palci. 2007. A new basal mosasauroid from the Cenomanian (U. Cretaceous) of Slovenia with a review of mosasauroid phylogeny and evolution. Journal of Vertebrate Paleontology 27:863-880.

Caldwell, M. W., L. A. Budney, and D. O. Lamoureux. 2003. Histology of tooth attachment tissues in the Late Cretaceous mosasaurid Platecarpus. Journal of Vertebrate Paleontology 23:622-630.

Carpenter, K. 2008. Vertebrate biostratigraphy of the Smoky Hill Chalk (Niobrara Formation) and the Sharon Springs Member (Pierre Shale); pp. 421-437 in P. J. Harries (ed.). High-resolution Approaches in Stratigraphic Paleontology. Springer, Dordrecht.

Carr, T. D. 1999. Craniofacial ontogeny in Tyrannosauridae (Dinosauria, Coelurosauria). Journal of Vertebrate Paleontology 19:497-520.

Conrad, J. 2008. Phylogeny and systematics of Squamata (Reptilia) based on morphology. Bulletin of the American Museum of Natural History 310:1-182.
Cuthbertson, R. S., and R. B. Holmes. 2015. A new species of Plioplatecarpus (Mosasauridae, Plioplatecarpinae) from the Bearpaw Formation (Campanian, Upper Cretaceous) of Montana, USA. Journal of Vertebrate Paleontology 35:e922980. https://doi.org/10.1080/02724634.2014.922980

Cuthbertson, R. S., J. C. Mallon, N. E. Campione, and R. B. Holmes. 2007. A new species of mosasaur (Squamata: Mosasauridae) from the Pierre Shale (lower Campanian) of Manitoba. Canadian Journal of Earth Sciences 44:593-606.

Cuthbertson, R. S., H. C. Maddin, R. B. Holmes, and J. S. Anderson. 2015. The braincase and endosseous labyrinth of Plioplatecarpus peckensis (Mosasauridae, Plioplatecarpinae), with functional implications for locomotor behavior. Anatomical Record 298:1597-1611.

de Beer, G. R. 1985. The Development of the Vertebrate Skull. University of Chicago Press, Chicago, 554 pp.

Emerson, S. B., and D. M. Bramble. 1993. Scaling, allometry, and skull design;pPp. 384-421 in J. Hanken and B. K. Hall (eds.). The Skull, Volume 3: Functional and Evolutionary Mechanisms. University of Chicago Press, Chicago.

Everhart, M. J. 2001. Revisions to the biostratigraphy of the Mosasauridae (Squamata) in the Smoky Hill Chalk Member of the Niobrara Chalk (Late Cretaceous) of Kansas. Transactions of the Kansas Academy of Science 104:59-78.

Everhart, M. J. 2002. New data on cranial measurements and body length of the mosasaur, Tylosaurus nepaeolicus (Squamata; Mosasauridae), from the Niobrara Formation of western Kansas. Transactions of the Kansas Academy of Science 105:33-43.

Everhart, M. J. 2005. Tylosaurus kansasensis, a new species of tylosaurine (Squamata, Mosasauridae) from the Niobrara Chalk of western Kansas, USA. Netherlands Journal of Geosciences 84:231-240.

Everhart, M. J. 2008. A bitten skull of Tylosaurus kansasensis (Squamata: Mosasauridae) and a review of mosasaur-on-mosasaur pathology in the fossil record. Transactions of the Kansas Academy of Science 111:251-262.

Everhart, M. J. 2017. Oceans of Kansas: a Natural History of the Western Interior Sea (second edition). Indiana University Press, Bloomington, $490 \mathrm{pp}$.

Field, D. J., A. LeBlanc, A. Gau, and A. D. Behlke. 2015. Pelagic neonatal fossils support viviparity and precocial life history of Cretaceous mosasaurs. Palaeontology 58:401-407.

Gilmore, C. W. 1927. Note on a second occurrence of the mosasaurian reptile Globidens. Science 6:452.

Gould, S. J. 1966. Allometry and size in ontogeny and phylogeny. Biological Reviews 41:587-638.

Hammer, Ø., D. A. T. Harper, and P. D. Ryan. 2001. PAST: Palaeontological Statistics software package. Palaeontologia Electronica 4(1):4. http://palaeo-electronica.org/2001_1/past/ issue1_01.htm.

Hampton, P. M. 2014. Allometry of skull morphology, gape size and ingestion performance in the banded watersnake (Nerodia 
fasciata) feeding on two types of prey. Journal of Experimental Biology 217:472-478.

Herrel, A., and J. C. O'Reilly. 2005. Ontogenetic scaling of bite force in lizards and turtles. Physiological and Biochemical Zoology 79:31-42.

Holmes, R. 1996. Plioplatecarpus primaevus (Mosasauridae) from the Bearpaw Formation (Campanian, Upper Cretaceous) of the North American Western Interior Seaway. Journal of Vertebrate Paleontology 16:673-687.

Hone, D. W., A. A. Farke, and M. J. Wedel. 2016. Ontogeny and the fossil record: what, if anything, is an adult dinosaur? Biology Letters 12:20150947. doi: 10.1098/rsbl.2015.0947.

Jiménez-Huidobro, P., and M. W. Caldwell. 2016. Reassessment and reassignment of the early Maastrichtian mosasaur Hainosaurus bernardi Dollo, 1885, to Tylosaurus Marsh, 1872. Journal of Vertebrate Paleontology 36:e1096275. https://doi.or g/10.1080/02724634.2016.1096275.

Jiménez-Huidobro, P., T. R. Simōes, and M. W. Caldwell. 2016. Re-characterization of Tylosaurus nepaeolicus (Cope, 1874) and Tylosaurus kansasensis (Everhart, 2005): Ontogeny or sympatry? Cretaceous Research 65:68-81.

Jiménez-Huidobro, P., M. W. Caldwell, I. Paparella, and T. S. Bullard. 2018. A new species of tylosaurine mosasaur from the upper Campanian Bearpaw Formation of Saskatchewan, Canada. Journal of Systematic Palaeontology. DOI: 10.1080/14772019.2018.1471744

Konishi, T., and M.W. Caldwell. 2010. Redescription of the holotype of Platecarpus tympaniticus Cope, 1869 (Mosasauridae: Plioplatecarpinae) and its implications for the alpha taxonomy of the genus. Journal of Vertebrate Paleontology 30:1410-1421.

Lee, M. S. Y. 1997. The phylogeny of varanoid lizards and the affinities of snakes. Philosophical Transactions of the Royal Society of London B 352:53-91.

Lindgren, J., C. Alwmark, M. W. Caldwell, and A. R. Fiorillo. 2009. Skin of the Cretaceous mosasaur Plotosaurus: implications for aquatic adaptations in giant marine reptiles. Biology Letters 5:528-531.

Lindgren, J., M. W. Caldwell, T. Konishi., and L. M. Chiappe. 2010. Convergent evolution in aquatic tetrapods: insights from an exceptional fossil mosasaur. PLoS ONE 5:e11998. https:// doi.org/10.1371/journal.pone.0011998.

Lindgren, J., H. F. Kaddumi, and M. J. Polcyn. 2013. Soft tissue preservation in a fossil marine lizard with a bilobed tail fin. Nature Communications 4: 2423. doi:10.1038/ncomms3423.

Lingham-Soliar, T. 1992. The tylosaurine mosasaurs (Reptilia, Mosasauridae) from the upper Cretaceous of Europe and Africa. Bulletin de l'Institut Royal des Sciences Naturelles de Belgique, Sciences de la Terre 62:171-194.

Lyons, P. D., M. Rioux, and R. T. Patterson. 2000. Application of a three-dimensional color laser scanner to paleontology: an interactive model of a juvenile Tylosaurus sp. basisphenoid-basioccipital. Palaeontologia Electronica 3(2):4. https:// palaeo-electronica.org/2000_2/mosasaur/issue2_00.htm

Openshaw, G. H., and J. S. Keogh. 2014. Head shape evolution in monitor lizards (Varanus): interactions between extreme size disparity, phylogeny and ecology. Journal of Evolutionary Biology 27:363-373.

Openshaw, G. H., D. C. D’Amore, M. Vidal-García, and J. S. Keogh. 2016. Combining geometric morphometric analyses of multiple 2D observation views improves interpretation of evolutionary allometry and shape diversification in monitor lizard (Varanus) crania. Biological Journal of the Linnean Society 120:539-552.

Pellegrini, R. 2007. Skeletochronology of the limb elements of mosasaurs (Squamata; Mosasauridae). Transactions of the Kansas Academy of Science 110:83-99.

Russell, D. A. 1967. Systematics and morphology of American mosasaurs. Bulletin of the Peabody Museum of Natural History 23:1-241.

Scannella, J. B., and J. R. Horner. 2010. Torosaurus Marsh, 1891, is Triceratops Marsh, 1889 (Ceratopsidae: Chasmosaurinae): synonymy through ontogeny. Journal of Vertebrate Paleontology 30:1157-1168.

Thurmond, J. T. 1969. Notes on mosasaurs from Texas. Texas Journal of Science 21:69-79.

Williston, S. W. 1898. Mosasaurs. University Geological Survey of Kansas 4:81-347. 
Appendix 1. Tylosaurus proriger measurements used in the allometric analysis (modified from Russell, 1967 and Everhart, 2002). All measurements in mm. TMP 1982.050.0010 is a cast of LACM 28964; ROM 59785 is a cast of a private specimen ("Sophie") at Triebold Paleontology, Inc. Abbreviations: BSL, basal skull length (premaxilla to occipital condyle).

\begin{tabular}{|c|c|c|c|c|c|c|c|c|}
\hline Specimen number & BSL & $\begin{array}{l}\text { Length of } \\
\text { premaxillary } \\
\text { rostrum }\end{array}$ & $\begin{array}{l}\text { Width of frontal } \\
\text { between orbits }\end{array}$ & $\begin{array}{l}\text { Length between } \\
\text { first and sixth } \\
\text { maxillary tooth }\end{array}$ & $\begin{array}{l}\text { Height of } \\
\text { quadrate }\end{array}$ & $\begin{array}{l}\text { Length of } \\
\text { lower jaw }\end{array}$ & $\begin{array}{l}\text { Length of } \\
\text { dentary }\end{array}$ & $\begin{array}{l}\text { Length between } \\
\text { first and sixth } \\
\text { dentary tooth }\end{array}$ \\
\hline USNM 6086 & 585 & $?$ & 118 & 142 & 79 & 650 & 373 & 163 \\
\hline AMNH 4909 & 600 & 45 & 113 & 146 & 78 & 686 & 402 & 143 \\
\hline USNM 8898 & 710 & $?$ & $?$ & 223 & $?$ & 935 & 565 & 215 \\
\hline AMNH 221 & $?$ & ? & $?$ & $?$ & ? & 160 & $?$ & $?$ \\
\hline FFHM 1997-10 & 1016 & 61 & 190 & 284 & 150 & 1220 & 667 & 251 \\
\hline FHSM VP-3 & 1080 & 60 & 180 & 250 & 150 & 1230 & 660 & 230 \\
\hline KUVP-1032 & 1195 & $?$ & $?$ & $?$ & $?$ & $?$ & ? & ? \\
\hline CMN 8162 & 574 & 42.5 & 110 & 127 & 71 & 575 & 364 & 172 \\
\hline GSM 1 & 980 & 62 & 227 & 241 & 133 & 1092 & 603 & 223 \\
\hline TMP 1982.050.0010 & 810 & 46 & 161 & 186 & 111 & 872 & 543 & 174 \\
\hline KUVP 66129 & 506 & $?$ & 93 & 147 & 52 & $?$ & 387 & 120 \\
\hline FFHM 1997-10 & 1061 & $?$ & 203 & 272 & 145 & 1177 & 703 & 244 \\
\hline YPM VPPU 012000 & 931 & $?$ & 205 & $?$ & $?$ & $?$ & $?$ & $?$ \\
\hline ROM 7906 & 1005 & 53 & 235 & 256 & 144 & 1245 & ? & 235 \\
\hline ROM 59785 & 1360 & 61 & 285 & 307 & 184 & 1550 & 814 & 296 \\
\hline
\end{tabular}

